
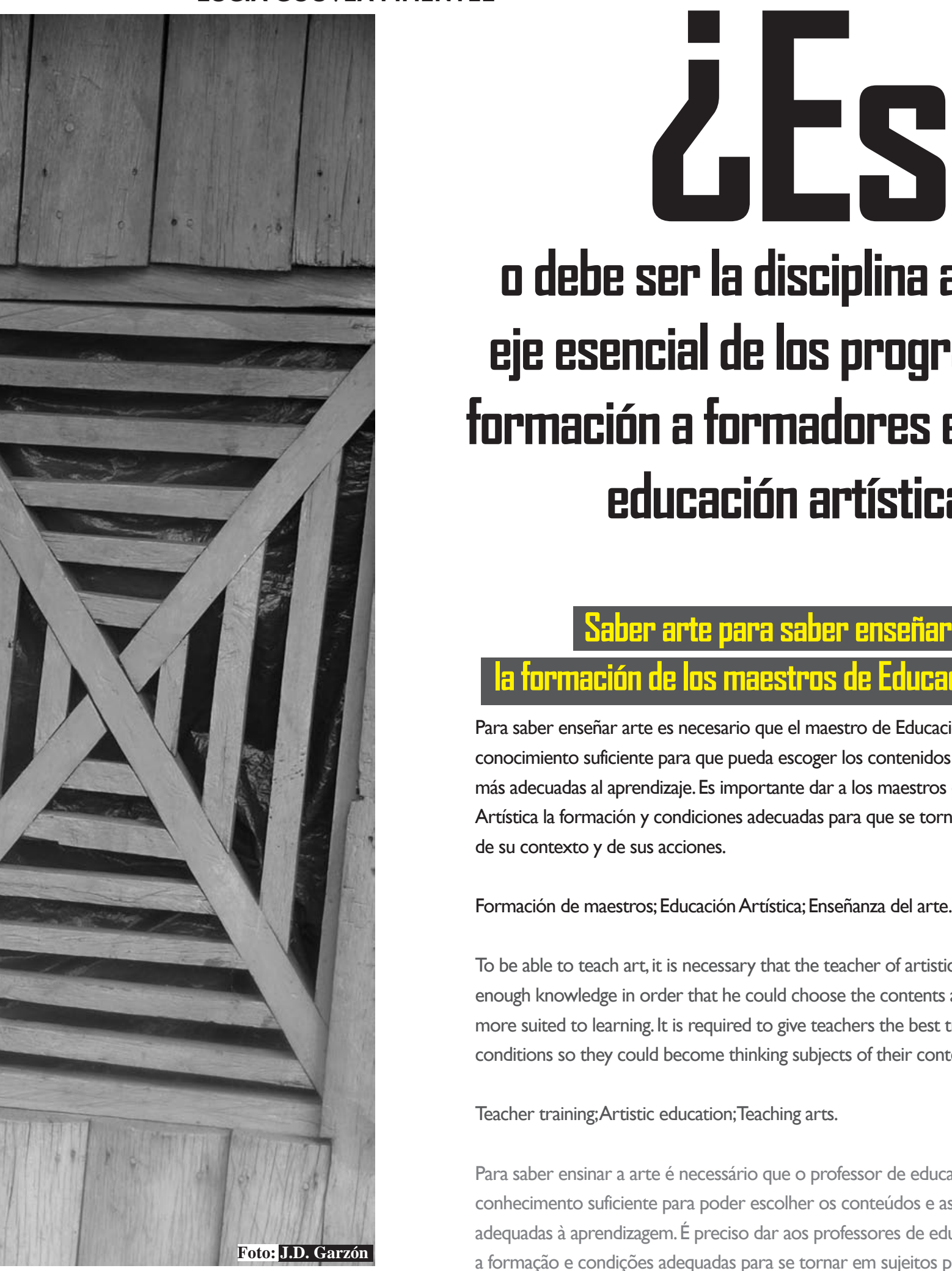

\title{
o debe ser la disciplina artística eje esencial de los programas de formación a formadores en artes y educación artística?
}

\section{Saber arte para saber enseĩar arte: \\ la formarión de los maestros de Eduración Artística}

Para saber enseñar arte es necesario que el maestro de Educación Artística tenga conocimiento suficiente para que pueda escoger los contenidos y las metodologías más adecuadas al aprendizaje. Es importante dar a los maestros de Educación Artística la formación y condiciones adecuadas para que se tornen sujetos pensantes de su contexto y de sus acciones.

Formación de maestros; Educación Artística; Enseñanza del arte.

To be able to teach art, it is necessary that the teacher of artistic education has enough knowledge in order that he could choose the contents and methodologies more suited to learning. It is required to give teachers the best training and proper conditions so they could become thinking subjects of their context and their actions.

Teacher training;Artistic education;Teaching arts.

Para saber ensinar a arte é necessário que o professor de educação artística tenha conhecimento suficiente para poder escolher os conteúdos e as metodologias mais adequadas à aprendizagem. É preciso dar aos professores de educação artística a formação e condições adequadas para se tornar em sujeitos pensantes de seu contexto e de suas ações.

Formação de professores; Educação artística; Ensino da arte. 
En primera instancia, debo aclarar que la disciplina en Brasil, se denomina Arte y abarca, en la Educación Básica (6 - 17 años), las áreas de Artes Audiovisuales, Artes Visuales, Danza, Música y Teatro. La propuesta consiste en disponer un maestro para cada una de ellas y que el alumno viva experiencias artísticas en todas las áreas durante el período en que se encuentra en la escuela. Lo anterior se logra, por el momento, en pocas escuelas, sobre todo en las públicas ligadas a universidades $\circ$ en centros de formación artística.

Arte en la escuela, es la oportunidad que tiene una persona para indagar, construir y aumentar conocimientos, desarrollar habilidades, articular y realizar trabajos estéticos y explorar sus sentimientos. Proporciona medios de conocer, presentar, interpretar, simbolizar y metaforizar en un contexto de apreciación y valoración. En suma, la enseñanza del Arte debe posibilitar a todos los alumnos la construcción de conocimientos en interacción con su emoción, a través del pensar, apreciar y hacer arte. Produciendo trabajos artísticos y conociendo la producción de otras culturas, el alumno podrá comprender la diversidad de valores que orientan tanto sus propios modos de pensar y actuar como los de otras sociedades.

Es importante que los alumnos comprendan el sentido del hacer artístico, es decir, entiendan que sus experiencias al dibujar, pintar, cantar, danzar, apreciar, filmar, dramatizar etc. no son actividades para distraerlos de la seriedad de las otras áreas, sino vivencias esenciales para la producción de conocimiento en el arte.

Enseñar arte significa, por supuesto, posibilitar experiencias y vivencias significativas en apreciación, reflexión y elaboración artística. Para esto, es necesario que el maestro posea una base teórica y práctica que le posibilite un pensamiento amplio, tanto para conocer los caminos recorridos por sus estudiantes como para propiciar momentos significativos que posibiliten encontrar nuevos procesos individuales y colectivos. Es necesario dar a los maestros de Arte la formación y condiciones adecuadas para que se tornen sujetos pensantes de su contexto y de sus acciones. El maestro de Educación Artística, merece ser respetado en toda su potencialidad y necesita tener condiciones para estudiar, elaborar materiales y actuar artísticamente, haciendo de sus clases momentos de acción creativa.

En la educación del maestro, se asume que para enseñar arte, éste debe tener una formación artística y pedagógica específica y sólida.Tener formación artística sólida no significa que el maestro sea un artista reconocido por los medios, con exposiciones frecuentes en galerías, museos y salones de arte; pero sí se requiere que vivencie el proceso artístico en el área de expresión en la cual actúa.Aquí vamos a hacer una diferenciación entre experiencia y vivencia.

Experiencia es aquello que tenemos una vez, que nos afecta, pero que puede o no repetirse. Puedo tener una experiencia en música, pero nunca más me dedico a estudiarla, entonces, recuerdo algunas cosas, pero no puedo ser considerada una persona que sabe Música.

LaVivencia es constante. Se inicia con la experiencia y se prolonga durante la vida. Usando el ejemplo de arriba: tuve una primera experiencia en música y decidí dedicarme a estudiarla; entonces, vivencio la música como intérprete o como público asiduo.

La vivencia en el arte y sobre el arte es esencial para que el maestro pueda elegir los contenidos que serán desarrollados con cada grupo de alumnos y sepa también, cómo cambiar el rumbo cuando sea necesario.

La vivencia en el arte se caracteriza por la práctica artística constante, aquella que se realiza con la intención de elaborar un objeto artístico, sea él, perenne o efimero.

La vivencia sobre el arte se refiere al estudio de las teorías sobre arte: historia, filosofía, sociología, crítica del arte, etc.

Ambas deben hacer parte de la formación inicial del maestro de Educación Artística, teniendo en cuenta que al momento de entrar en acción en la escuela, tendrá que ofrecer a sus estudiantes, tanto actividades teóricas como prácticas. Desarrollar el potencial cognitivo y creativo de los alumnos es una consecuencia del entorno, generado principalmente, por el maestro.

Ahora bien, el conocimiento de la práctica pedagógica es esencial para que pueda desarrollar los contenidos de manera adecuada, eligiendo estrategias didácticas eficaces para el aprendizaje $y$, construyendo metodologías de evaluación coherentes con los objetivos de lo que fue enseñado.

Así, un curso de formación inicial de maestros de Educación Artística debe contemplar las teorías y prácticas artísticas y las teorías y prácticas 
pedagógicas; y debe además, equilibrarlas. Unas no son más importantes que las otras y es en el equilibrio, donde reside gran parte del éxito del proceso de enseñanza/aprendizaje del Arte. Su formación, por tanto, tiene que desarrollarse con mucho cuidado.

A modo de ejemplo, presento el cuadro con las disciplinas y su lugar en el Currículo del Curso de Licenciatura en ArtesVisuales de la Escuela de Bellas Artes de la Universidad Federal de Minas Gerais en Brasil - EBA/UFMG.

\section{Curso: Artes Visuales - Modalidad: Licenciatura}

\section{PERIODO}

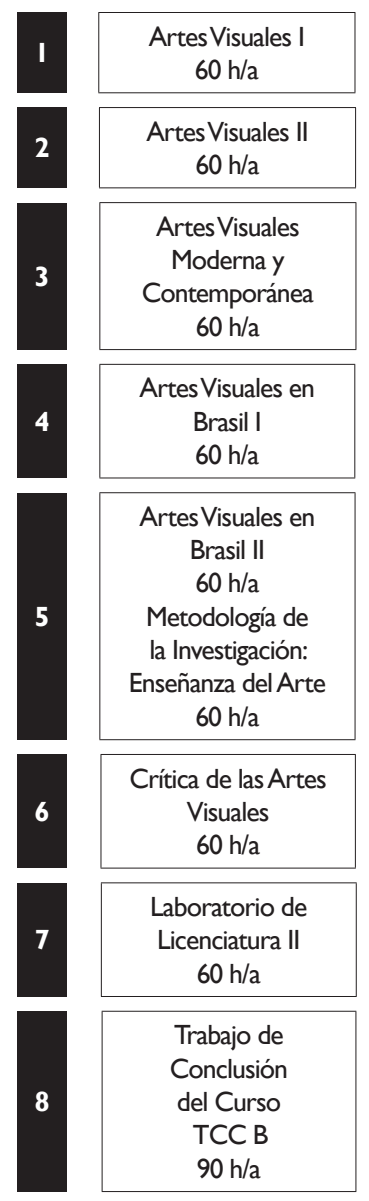

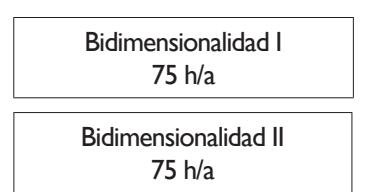
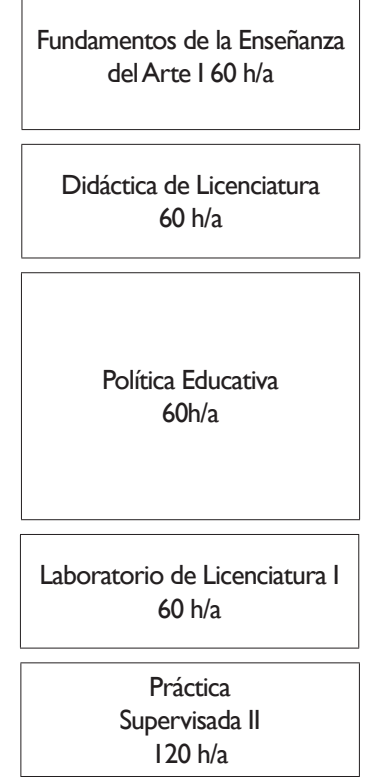

Práctica Supervisada III $165 \mathrm{~h} / \mathrm{a}$
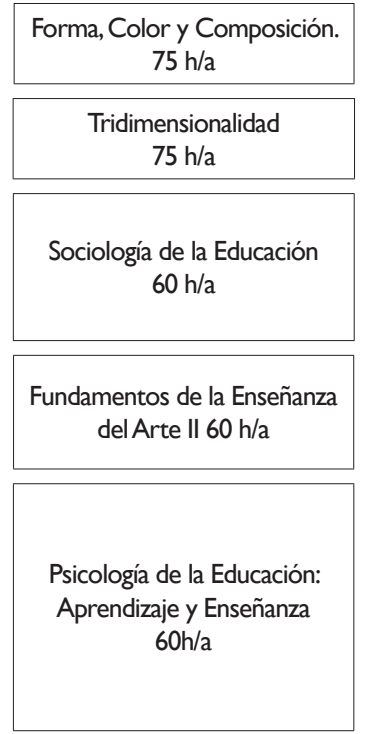

Práctica Supervisada I $120 \mathrm{~h} / \mathrm{a}$

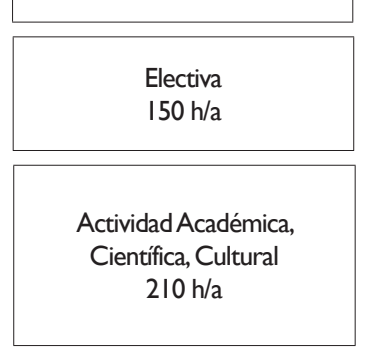

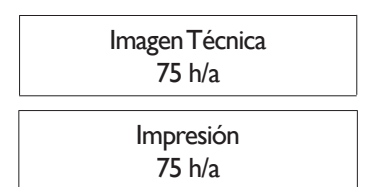
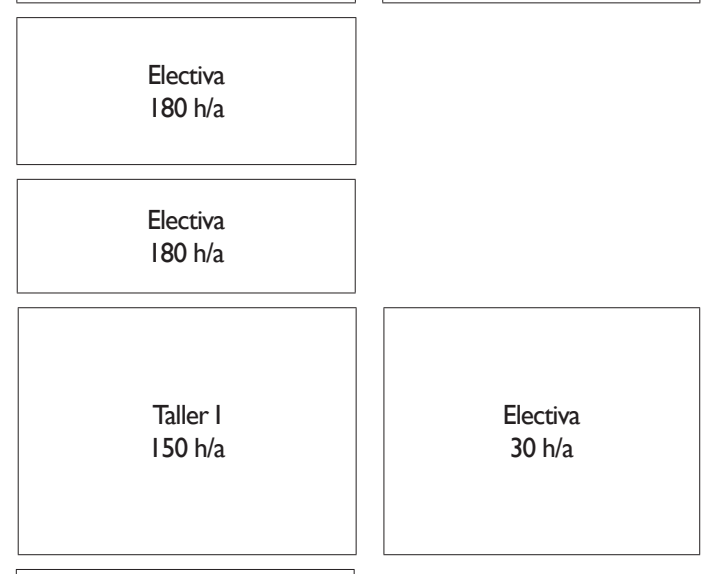

Electiva

$105 \mathrm{~h} / \mathrm{a}$
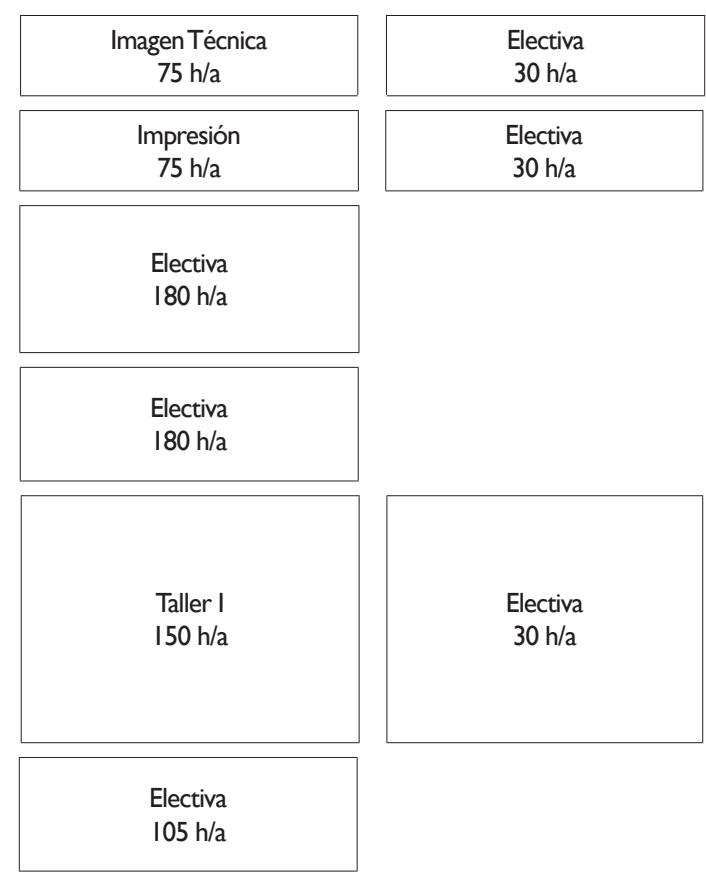

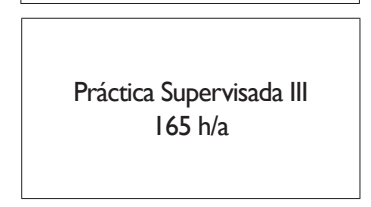

No obstante, necesitamos también pensar en la formación continuada de estos profesionales, ya que el arte no es una área de conocimiento estática, pues se renueva constantemente $y$, por tanto, el maestro necesita actualización permanente, tanto teórica como práctica.

Hoy en día, la educación a distancia es una oportunidad de enseñanza que se presenta como eficaz y posible. Lo que se necesita es una infraestructura adecuada y de maestros capacitados para hacerlo. No basta en EAD, saber sólo el contenido, es necesario saber cómo enseñarlo a distancia, sin la presencia física del alumno en el aula de clase. En un curso de artes visuales es también necesario que se realicen clases presenciales en los talleres, pues es común que la practica se efectúe por imitación y discusión acerca de: ¿cómo hago yo?,y ¿cómo Lo que se busca:

- Maestros que estén dispuestos a invertir en sí mismos como especialistas en Arte.

- Maestros que estén dispuestos a invertir en la preparación de clases y materiales adecuados para los alumnos que tienen, y no en comprar materiales listos o en que sean entrenados.

La obra de arte se hace para ser vista, escuchada y disfrutada. Podemos caminar por ella (como en una instalación), podemos tenerla en casa, podemos cantarla, danzarla o gesticularla. Su naturaleza es sensorial, no solamente ideal o conceptual. El universo de los sentidos es su campo. Hay elaboración y transformación de un medio, propone un material, un objeto sensorial dirigido a la sensibilidad y a la cognición. El objeto sensible es el punto de anclaje a partir del cual la obra puedes hacer tu? 
realiza otras operaciones. Cada área de expresión sincroniza su discurso estético con el discurso material - mediático que le es propio y necesario.

Ya sea que su desarrollo se encamine a permanecer en el tiempo y en el espacio, como en el caso de la pintura, la escultura o el grabado, por ejemplo; o que se encamine a ser consumido en el tiempo y en el espacio, como en la danza y en la música, la captura de movimientos de intensidad estética se da en instantes precisos, que pueden variar de acuerdo con factores contextuales, subjetivos y circunstanciales.

Educar para el arte es arte/educar para fijar esos momentos, para instalar esa captura, para perdurar esos instantes de forma que se tornen significativos como parte del sujeto que aprehende. Es saber que el acceso a las más diversas manifestaciones artísticas es un derecho humano y negarlo es quitar al educando parte visceral de su humanidad.

No se educa para el arte direccionando, encuadrando o formateando. Se educa para las artes indicando, proponiendo, mediando. Las imágenes homogeneizadas y las interpretaciones unidireccionales no sirven a la educación para las artes.

Es necesario considerar que la disculpa de que las clases de Educación Artística no son para formar artistas, no es procedente. ¿Acaso en la escuela las clases de Matemática están hechas para formar matemáticos? ¿O las de Historia para formar historiadores? Las áreas están en la escuela para el ejercicio de desarrollar el raciocinio artístico, matemático, histórico etc. Cada área del conocimiento tiene la responsabilidad de desarrollar el pensamiento propio del área; de esto resulta que la tarea de arte/educar es grande y compleja.Arte/educar es liberar,y para liberar es preciso instrumentalizar, propiciar experiencias y vivencias, y construir conocimientos en el arte.

Educar para el arte supone complicidad entre artista, obra, mediador y educando. La captura del instante puede efectuarse por cualquier vía. Lo importante es que ocurra y se desdoble en permanente, provocante e instigante dinámica. Ya que, arte/educar es un acto colectivo, social, que involucra sujetos al mismo tiempo: enseñantes $y$ aprendientes.

Pensar un currículo de formación de maestros de Educación Artística es un acto político y no se limita a decidir qué disciplinas deben ser cursadas por los alumnos que serán futuros maestros; pero sí decidir, qué tipo de enseñanza se quiere promover $y$, por lo tanto, qué tipo de ciudadanos queremos para nuestro país.

LUCIA GOUVÊA PIMENTEL. Profesora Titular de la Escuela de Bellas Artes de La Universidad Federal de Minas Gerais, UFMG - Brasil; Secretaria General del CLEA; Representante porAmérica del Sur en el Consejo Mundial de la INSEA. luciagpi.bh@terra.com.br 